\title{
Tratamento de fluorose dentária causada por dentifrício com a técnica de microabrasão de esmalte: relato de caso clínico
}

\author{
Treatment of dental fluorosis caused by dentifrice with the technique of enamel microabrasion: \\ clinical case report \\ Tratamiento de la fluorosis dental causada por dentifrice con la técnica de la microabrasión del \\ esmalte: reporte de caso clínico
}

\begin{abstract}
Resumo
A fluorose dentária resulta da ingestão de pequenas quantidades de flúor durante um longo período de tempo, podendo afetar os tecidos mineralizados, o osso e o esmalte dentário. O período crítico ocorre dos 15 aos 30 meses, quando os incisivos permanentes estão em transição entre a fase secretora e a fase de maturação do esmalte. O objetivo deste artigo é relatar um caso clínico apresentando a técnica de microabrasão de esmalte como opção eficaz de tratamento de fluorose dentária classificada como moderada. Relato de caso: Paciente 12 anos do sexo feminino, procurou a clínica, com lesões nos elementos 11,21 . Sua genitora relatou ingestão de creme dental durante seus primeiros anos de vida, o qual ficava ao alcance da paciente. A mesma não sabe informar a quantidade ingerida ou mesmo a frequência do ato. O diagnóstico é de suma importância para a indicação e sucesso do tratamento. A microabrasão foi realizada com pasta profilática e pedra pomes, realizando movimentos circulares com o auxílio de uma espátula de madeira foi suficiente e resolveu o problema estético que envolvia as manchas no esmalte da paciente de forma rápida e segura. É recomendado a utilização dessa técnica quando o diagnóstico for de alteração decorrente de fluorose leve a moderada. Palavras-chave: Fluorose dentária; Microabrasão de esmalte; Dentifrícios.
\end{abstract}

\begin{abstract}
Dental fluorosis results from the ingestion of small amounts of fluoride over a long period of time, which can affect mineralized tissues, bone and tooth enamel. The critical period occurs from 15 to 30 months, when the permanent incisors are in transition between the secretory phase and the enamel maturation phase. The purpose of this article is to report a clinical case presenting the enamel microabrasion technique as an effective treatment option for dental fluorosis classified as moderate: Case report. The correct diagnosis is extremely important for the indication and success of the treatment. The microabrasion of the dental enamel was sufficient and solved the patient's aesthetic problem quickly and safely. It is recommended to use this technique when the diagnosis is alteration due to mild to moderate fluorosis.
\end{abstract}

Keywords: Dental fluorosis; Enamel microabrasion; Toothpaste.

\section{Resumen}

La fluorosis dental es el resultado de la ingestión de pequeñas cantidades de fluoruro durante un período prolongado. período de tiempo, que puede afectar los tejidos mineralizados, los huesos y el esmalte de los dientes. La período crítico ocurre de 15 a 30 meses, cuando los incisivos permanentes están en transición entre la fase secretora y la fase de maduración del esmalte. La El propósito de este artículo es reportar un caso clínico que presenta la microabrasión del esmalte técnica como una opción de tratamiento eficaz para la fluorosis dental clasificada como moderada: Reporte 
de un caso. El diagnóstico correcto es extremadamente importante para la indicación y éxito del tratamiento. La microabrasión del esmalte dental fue suficiente y resolvió el problema estético del paciente de forma rápida y segura. Se recomienda utilizar esta técnica cuando el diagnóstico es una alteración por fluorosis leve a moderada.

Palabras clave: Fluorosis dental; Microabrasión de esmalte; Pasta dental.

\section{Introdução}

A doença cárie é uma disbiose, açúcar dependente que traz danos às estruturas do dente e pode resultar em lesões cariosas quando os eventos de desmineralização superam os de remineralização (Araujo, 2019; Lima, 2007). Entre as doenças bucais a cárie dental é a mais comum mundialmente. Seu controle inclui estratégias múltiplas direcionadas ao risco e atividade de cárie de cada indivíduo (Maltz, 2016; Lima, 2020). O flúor é o principal fator contribuinte para a prevenção da cárie (Cury, 2002; Narvai, 2000).

Age interferindo no processo de desmineralização e remineralização do esmalte dentário (Garbin, 2017; Lima, 2007). A ação do flúor na cavidade bucal, não depende somente da ingestão por meio da água, o fator local é o mais importante, pois é necessário que seja mantido constantemente na cavidade bucal (Cury, 2002) Podem ser aplicados profissionalmente por meio de géis, vernizes, dispositivos e soluções de liberação lenta ou individual: creme dental e enxaguantes bucais. São recomendados para indivíduos considerados de risco moderado ou alto risco de cárie (Cury, 2002; Mullane, 2016).

A utilização do fluoreto como meio preventivo e terapêutico iniciou-se em 1945, com a fluoretação das águas de abastecimento público (Santos, 2013; Rahila, 2019: Lima, 2019; Lacerda, 2020). Em 1960 os dentifrícios fluoretados começaram a ser utilizados e é recomendado para prevenir e controlar a cárie juntamente com a técnica correta da escovação, na quantidade de 1000 ppm de flúor. Deve ser utilizado, desde o irrompimento do primeiro dente, mas é necessário a quantidade adequada (Walsh, 2019). Segundo a Food and Drug Administration (FDA) em crianças menores de 2 anos é recomendado uma quantidade de um grão de arroz cru. 3 a 6 anos, uma porção do tamanho de uma ervilha deve ser utilizado (Walsh, 2019; Wright, 2014).

No entanto, o flúor pode ser tóxico, e sua toxicidade pode ser aguda e crônica. Na aguda, o flúor é ingerido de uma só vez e, dependendo da dose submetida ao indivíduo, as consequências podem ser de irritação gástrica até a morte. A dose de 5,0 mg F/kg de peso corpóreo é considerada a dose provavelmente tóxica para intoxicação aguda (Cury, 2002; Wright, 2014).Por outro lado, a toxicidade crônica, resulta da ingestão de pequenas quantidades de flúor durante um longo período de tempo, sendo chamada de fluorose dental, podendo afetar os tecidos mineralizados, o osso e o esmalte dentário (Cury, 2001, Feuzer, 2006).

O período crítico ocorre em cerca de 15 a 30 meses, quando os incisivos permanentes estão em transição entre a fase secretora e a fase de maturação do esmalte. Nessa idade as crianças não sabem expectorar e acabam ingerindo de forma involuntária, apresentando risco para o desenvolvimento da fluorose (Lima; Cury, 2001). A gravidade da fluorose varia de acordo com o tempo de exposição ao flúor, idade, grau de nutrição do indivíduo, as manifestações clínicas são, discretas manchas esbranquiçadas nos dentes e a até uma significativa má formação do esmalte dentário (Aoba, 2002; Buzalaf, 2013; Miranda, 2019). Desta forma, o objetivo do presente estudo é relatar um caso clínico de técnica de microabrasão do esmalte como opção de tratamento da fluorose dentária.

\section{Relato de Caso}

Paciente de 12 anos de idade, sexo feminino, procurou atendimento odontológico na Clínica Odontológica do Centro Universitário Tiradentes - AL. Durante a anamnese, foi relatado pela sua responsável, história passada de ingestão de creme dental com flúor no decorrer de toda a sua primeira infância e que o creme dental fica ao alcance da criança. A queixa principal eram manchas brancas em todos os elementos das arcadas dentárias que interferiam em sua vida social. 
A responsável negou a presença de alergias, traumas anteriores ou quaisquer alterações dignas de nota. No exame clínico foi observada na dentição permanente a presença de manchas com linhas horizontais e estriadas esbranquiçadas nas superfícies de todos os dentes (Figuras 1 e 2). Sendo de maior incômodo, as manchas presentes nos incisivos centrais superiores (11 e 21) são classificadas como grau de severidade moderada. Com os dados da anamnese e do exame clínico, foi possível chegar ao diagnóstico de fluorose dentária.

O tratamento proposto foi a microabrasão, sob isolamento absoluto, com pedra pomes e ácido fosfórico a $37 \%$ (biodinâmica), na proporção volumétrica 1:1 (Queiroz, 2010), nos elementos dentários 11, 12, 13, 21, 22 e 23, com objetivo de recuperar a estética por meio de um mínimo desgaste superficial do esmalte (Queiroz, 2010). O responsável legal pela a criança, foi informado sobre o tratamento e assinou o termo de autorização no Centro Universitário Tiradentes. Inicialmente foi realizada a profilaxia com pedra pomes e água, seguida da lavagem e secagem das superfícies.

Realizou-se o isolamento absoluto (Figura 3), aplicação da pasta com mais ou menos $1 \mathrm{~mm}$ de espessura sobre as manchas no esmalte, e realização da microabrasão com a espátula de madeira (Junior, 2008) (Figura 4). No total, foram realizadas 7 aplicações de 10 segundos cada. Após cada aplicação, foi feita a lavagem abundante e análise da remoção das manchas com a superfície de esmalte úmida. Para concluir, realizou-se uma aplicação tópica de flúor (Figura 5).

Figuras 1 e 2 - Aspecto clínico inicial.

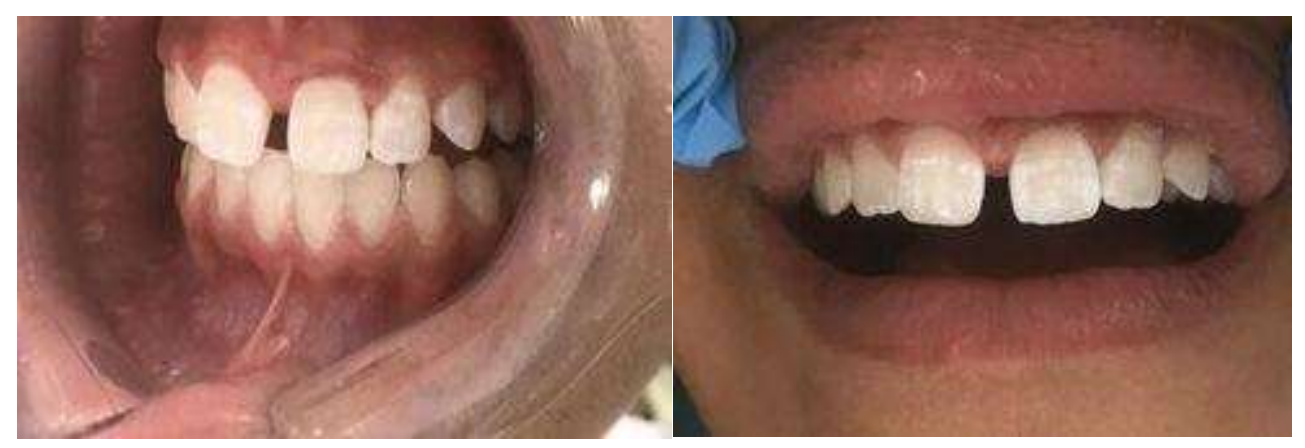

Fonte: Autores.

Figura 3 - Isolamento absoluto.

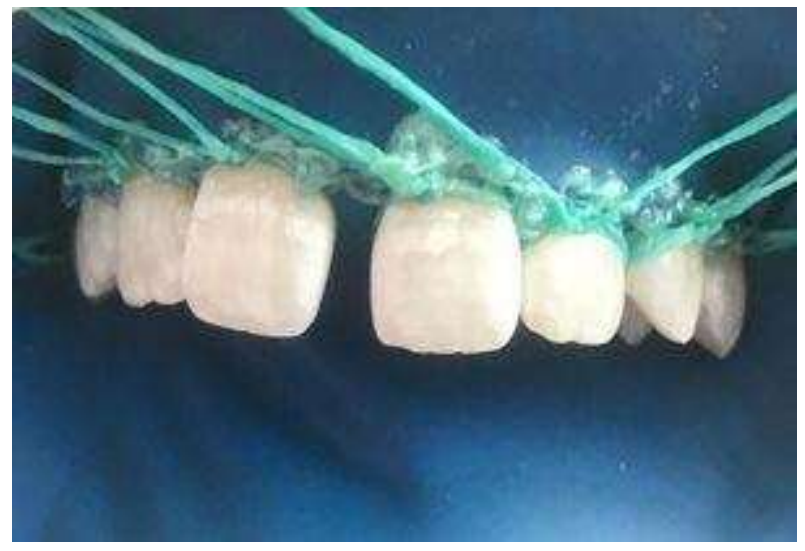

Fonte: Autores. 
Figura 4 - Realização da Microabrasão.

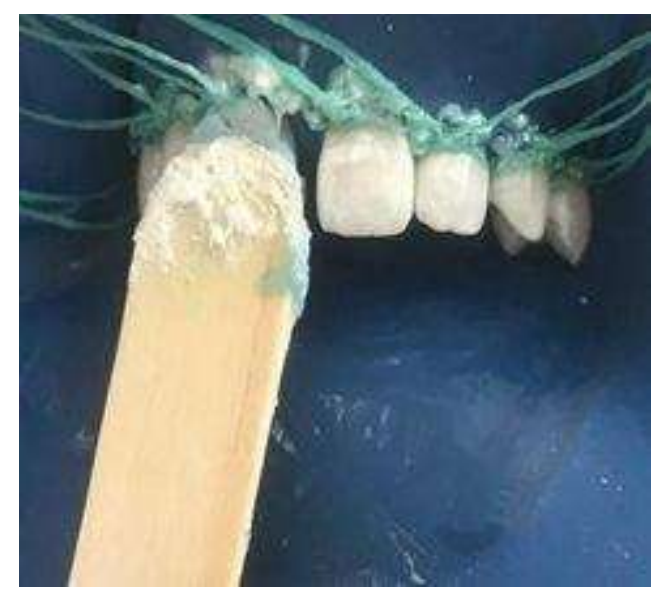

Fonte: Autores.

Figura 5 - Aplicação Tópica de flúor.

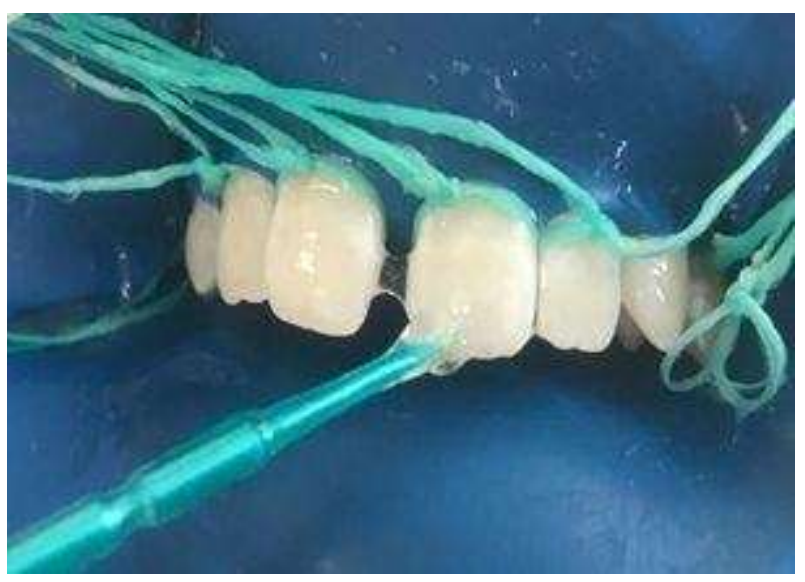

Fonte: Autores.

Figura 6 - Aspecto clínico final.

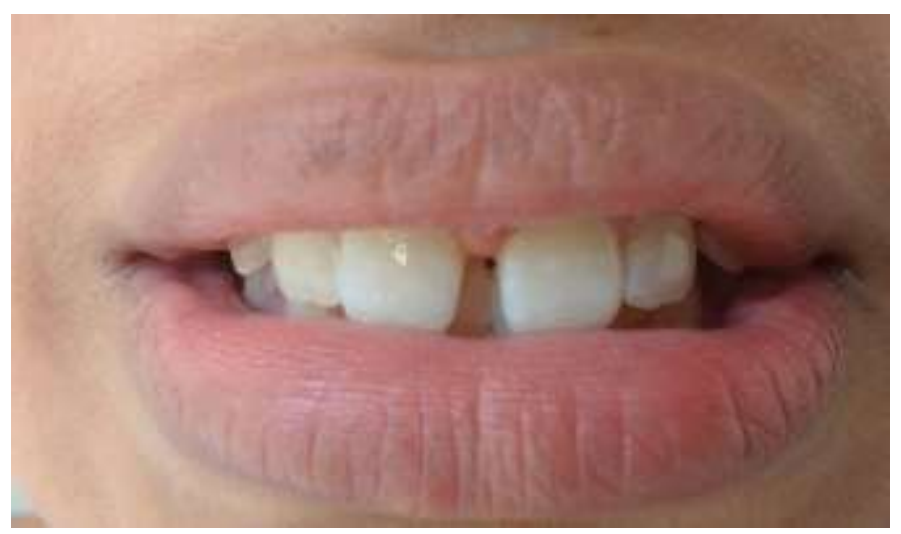

Fonte: Autores.

\section{Discussão}

A fluorose dental compromete a estética do indivíduo interferindo no bem estar social e psicológico. Na adolescência tem uma relevância mais acentuada em relação ao período da vida em que se encontram (Viegas et.al 2011). Alguns estudos 
mostram baixa autoestima nos pacientes acometidos pela fluorose principalmente nos incisivos centrais superiores que compromete suas atividades sociais, uma vez que a autoconfiança também é atingida (Rigo, 2015).

O flúor é benéfico na prevenção da cárie dentária, mas é necessário ter conhecimento sobre os riscos decorrentes da sua utilização (Rigo, 2015). A ingestão constante de doses acima das consideradas seguras, causa fluorose durante o período de formação dos dentes e da maturação do esmalte, e sua característica envolve aumento da porosidade do esmalte, deixandoo mais opaco (Feuzer, 2006).

Um dos motivos para o desenvolvimento desta patologia é a quantidade excessiva por ingestão prolongada do flúor contido nos dentifrícios (Cury, 2002). A escovação para crianças com idade inferior a 6 anos deve ser supervisionada pelos responsáveis, a colocação do dentifrício na escova deve ser equivalente a um grão de arroz cru. É necessário orientá-las ao cuspir e enxaguar a boca após a escovação (Lévy, 2003; Tan, 2005).

Existem diversas alternativas de tratamento que são preconizadas para a fluorose dentária. Um dos tratamentos, aborda procedimentos operatórios mais conservadores que envolvem produtos químicos afim de remover ou minimizar essas manchas de fluorose, existe também os procedimentos operatórios que implicam no desgaste de estrutura dental e na restauração por meio de resinas compostas, facetas laminadas e coroas metalocerâmicas e cerâmicas. No caso relatado, foi aplicado a técnica de Queiroz, 2010 (ácido fosfórico a 37\% e pedra pomes) a microabrasão foi suficiente por se tratar de manchas superficiais, no entanto, em alguns casos são verificadas manchas profundas, sendo necessário o restabelecimento da estética por meio da utilização de restaurações (Greenwall 2009; Nahsan, 2011). Uma das técnicas mais conservadoras para fluorose é a microabrasão do esmalte que remove somente a camada superficial do mesmo, esta é considerada eficaz quando corretamente aplicada, fácil e de rápida execução (Viegas, 2011).

É importante um correto diagnóstico e uma correta aplicação da técnica para obtenção do sucesso no tratamento da fluorose (Queiroz, 2010). É notório que a técnica de microabrasão do esmalte empregada foi eficaz e conservadora na remoção das manchas, mas deve ser usada com cautela evitando assim remoção de estrutura dental em excesso, um polimento posterior também deve ser realizado para manter a estética e evitar alteração da superfície (Viegas, 2011; Paic, 2008).

\section{Conclusão}

A ingestão de dentifrícios fluoretados é um fator de risco para a fluorose dentária. O correto diagnóstico é de suma importância para a indicação e sucesso do tratamento. A microabrasão do esmalte dental foi suficiente por se tratar de manchas superficiais, resolvendo o problema estético da paciente de forma rápida e segura, conservando a estrutura dentária. É recomendado a utilização dessa técnica quando o diagnóstico for de alteração decorrente de fluorose leve a moderada.

\section{Referências}

Araújo, F. M. L. (2019). Tratamento da doença cárie não cavitada com infiltrante resinoso.Trabalho de Conclusão de Curso (Bacharel em Odontologia) Centro Universitário do Planalto Central Apparecido dos Santos.

Aoba, T., \& Fejerkov, O. (2002). Dental Fluorosis: Chemistry and Biology. Crit Rev Oral Biol Med; 13(2): 155-70. 12.

Arsati, Y. B. de O. L., Gomes, A. R. L. F., Santos, H. K. A., Arsati, F., Oliveira, M. C., \& Freitas, V. S. (2018). Exposure to fluoride of children during the critical age for dental fluorosis, in the semiarid region of Brazil. Ciência \& Saúde Coletiva, 23(4):1045-1054.

Buzalaf, M., Kobayashi, C., Magalhães, A. C., \& Philippi, S. T. (2013). Fontes de ingestão de fluoretos. In: Buzalaf MAR. Fluoretos e saúde bucal. Santos; p.11-26.

Cury,J., Filho, A. P. R., Berti, F. L. P., \& Tabchoury, C. P. M (2019). Systemic Effects (Risks) of Water Fluoridation. Braz Dent J 30(5).

Cury, J. In. Baratieri, L. N., Monteiro Jr, S., Andrada, M. A. C., Vieira, L. C. C., Ritter, A. V., Cardoso, A. C. (2002). Uso do flúor e controle da cárie como doença. Odontologia restauradora: fundamentos e possibilidades. 31-68. 
Domingos, P. A. dos S., Donato, H. A. R., \& Russi, A. K. F. D. (2018). Riscos do uso do flúor sistêmico - Revisão de literatura. Journal of Research in Dentistry, 6(4):86-90.

Feuzer, L., Junior, S. M., \& Araújo, É. (2006). Fluorose na dentição decídua. Relato de caso clínico. Arquivos em Odontologia, Belo Horizonte, 42, 1, 2.

Garbin, C. A. S., Santos, L. F. P., Garbin, A. J. I., Moimaz, S. A. S., \& Saliba, O. (2017). Fluoridation of public water supply: bioethical, legal and political approach. Rev. bioét. (Impr.). 2017; 25 (2): 328-37.

Greenwall L. H. (2009). Treatment considerations for bleaching and bonding white lesions in the anterior dentition. The Alpha omegan, $102(4), 121-127$.

Júnior, R. P., Ribeiro, R. C., \& Lopes, T. S. P. (2008). Microabrasion as treatment of enamel fluorosis. RGO: Revista Gaúcha de Odontologia.

Lacerda, A. P. A. G., Oliveira, N. A., Pinheiro, H. H. C., Assis, K. M. de L., \& Cury, J. A. (2020). Fluoretação da água dos dez maiores municípios do estado do Tocantins, Brasil. Ciênc. saúde coletiva 25 (4).

Levy, S. M. (2003). An update on fluorides and fluorosis. J Can Dent Assoc, 69(5), 286-91.

Lima, E. de O. 2007). Cárie dentária: um novo conceito. Rev. Dent. Press Ortodon. Ortop. Facial 12(6).

Lima, I. F., Nóbrega, D. F., Cericato, G. O., Ziegelmann, P. K., \& Paranhos, L. R.(2019). Prevalência de fluorose dental em regiões abastecidas com água sem suplementação de flúor no território brasileiro: uma revisão sistemática e metanálise. Ciênc. saúde coletiva 24 (8).

Maltz, M., Groisman, S., Tenute, L. M. A., \& Cury, J. A. (2016). Cárie dentária: conceitos e terminologia. Cap, 1 p,13-16.

Miranda, A. R., Silva, A. E., Silva, G. F., Moura, P. K. A., Oliveira, S. A. M., \& Pimentel, M. C. M. M. (2019). Fluorose dental. Facs/Univale.

Mullane, D. M. O., Baez, R. J., Jones, S., Lennon, M. A., Peterson, P. E., Rugggunn, A. J., Whelton, H., \& Whitford, G. M. (2016) Fluoride and Oral Health. Community Dental Health.

Nahsan, F. P., da Silva, L. M., Baseggio, W., Franco, E. B., Francisconi, P. A., Mondelli, R. F., \& Wang, L. (2011). Conservative approach for a clinical resolution of enamel white spot lesions. Quintessence international (Berlin, Germany: 1985), 42(5), 423-426.

Narvai, P. C. (2000). Cárie dentária e flúor: uma relação do século XX. Ciência \& Saúde Coletiva, 5(2):381-392, 2000

Paic, M., Sener, B., Schug, J., \& Schmidlin, P. R. (2008). Effects of microabrasion on substance loss, surface roughness, and colorimetric changes on enamel in vitro. Quintessence international (Berlin, Germany: 1985), 39(6), 517-522.

Queiroz, V., et al. Report of two microabrasion techniques of enamel to remove stains and discussion. Rev. odontol. UNESP, 39(6), 369-372, 2010.

Rahila, C., Narayanan, M. B. A., Cumar, S. G. R., Selvamary, A. L., Sujatha, A., \& Kirubaharan, E. J. (2019). Association of COL1A2 (PvuII) gene polymorphism with risk and severity of dental fluorosis. A case control study, Saudi Dental Journal.

Rigo, L., Lodi, L., \& Garbin, R. R. (2015). Diagnóstico diferencial de fluorose dentária por discentes de odontologia. Einstein.13(4):547-54.

Santos, A. P. P., Oliveira, B. H., \& Nadanovsky, P.(2013). Effects of Low and Standard Fluoride Toothpastes on Caries and Fluorosis. Systematic Review and Meta-Analysis. Caries Res.

Santos, C. T., Picini, C., Czlusniak, G., \& Alves, F. B. T. (2014). Anomalias do esmalte dentário - revisão de literatura. Arch Health Invest 3(4)

Tan, B. S. \& Razak, I. A. (2005) Fluoride exposure from ingested toothpaste in 4-5-year-old Malaysian children. Community Dent Oral Epidemiol, 33, 31725 .

Walsh, T., Worthington, H., Glenny, A. M., Marinho, V. C. C., \& Jeroncioc, A. (2019). Fluoride toothpastes of different concentrations for preventing dental caries. Cochrane Database Syst Rev.

Wright, J. T., Hanson, N., Ristic, H., Whall, C. W., Estrich, C. G., \& Zentz, R. R. (2014). Fluoride toothpaste efficacy and safety in children younger than 6 years: a systematic review. J Am Dent Assoc.

Viegas, C. M., Scarpelli, A. C., Novais Jr, J. B., Paiva, S. M., \& Pordeus, I. A. (2011). Fluorose dentária: abordagens terapêuticas para recuperação estética $R G O$ - Rev Gaúcha Odontol., 59, 497-501.2011. 